\title{
Benchmarking the effectiveness of mitigation measures to the quality of environmental impact statements: lessons and insights from mines along the Great Dyke of Zimbabwe
}

\author{
Patrick Gwimbi \& Godwell Nhamo
}

\begin{abstract}
The environmental impact statement (EIS) plays an important role in informing decision makers about the likely impacts of development projects on the environment and suggesting mitigation measures for addressing such impacts. Increased effort to improve the quality of EIS has been a focus on its proposed mitigation measures and their likely effectiveness. There is, however, a lack of such studies in Zimbabwe's mining industry. Following a conceptual framework of EIS quality as an indicator of mitigation effectiveness, this paper assesses the quality of EIS and its likely influence on the effectiveness of its proposed mitigation measures. Twenty-two purposively sampled EISs for mines operating along the Great Dyke of Zimbabwe were reviewed using the modified Lee and Colley (Review of the quality of environmental statements, Manchester EIA Centre, University of Manchester, Manchester 1992) quality review package and Mitchell's (EA the Magazine of IEA and EARA 28-29, 1997) mitigation hierarchy guidelines. Results show that $77 \%$ of the EISs are of satisfactory quality, while $51 \%$ of the proposed mitigation measures focus on adverse impact reduction. The deficiencies are traced to vagueness in the regulations regarding baseline data collection and analysis and conceptualization of mitigation. Based on the results, it is suggested that more efforts should be aimed at reviewing the EIA regulations in order to improve the quality of EISs.
\end{abstract}

Keywords Environmental impact statement Review area Environmental impact assessment Mining Great Dyke Effectiveness Mitigation Zimbabwe

\section{Introduction}

The quality of environmental impact statement (EIS) is often used as a major indicator of environmental impact assessment (EIA) effectiveness (Morrison-Saunders et al. 2001; Sadler 1996). As a technical document, the ElS provides mitigation measures which address adverse impacts of project development activities and enhance the quality of human health through its influence on decision making (Glasson et al. 2005; Canelas et al. 2005; Evans 2013). The evaluation of ElS is therefore very important to validate its information and likely effectiveness in protecting the environment from development activities (Okafor 2008; Sok 2014). However, while several studies have been carried out at international level on the quality of EISs (Pinho et al. 2007; Sandham et al. 2008; Kabir et al. 2010), there is paucity of such information in Zimbabwe. This paper arose from an attempt to fill this gap.

Mitigation is a key review area in EIS and lies at the heart of EIA (Wood 2003). The argument in the literature is that it is the role of EIS to relay its proposed mitigation measures in an accurate and understandable manner in order for informed decisions to be taken (Pinho et al. 2007; Sandham et al. 2008; Kabir et al. 2010). Pinho et al. (2007) argument is that, the effectiveness of mitigation measures is inextricably linked to the quality of EIS. This assertion is supported by Ortolano and Shepherd (1995) and Wende (2002), whose analysis of the impact of ElS quality on ElA effectiveness shows that there is a clear relationship between the two. According to Ortolano and Shepherd (1995), EIS illuminates environmental issues to be considered in making decisions and provides signs that make it known with a reasonable degree of certainty the effectiveness of such decisions.

In Zimbabwe, Part XI (99) (d) of the Environmental Management Act (Chapter 20:27), which became obligatory in 2003, requires project proponents with development projects likely to adversely impact on the environment to:

Specify the measures proposed for eliminating, reducing or mitigating any anticipated adverse effects the project may have on the environment, identifying ways of monitoring and managing the environmental effects of the project (Government of Zimbabwe (GOZ) 2003: 391).

The regulations require project proponents to produce detailed EISs on the environmental impacts of the proposed actions, its alternatives, and any available mitigation measures. Since the inception of the regulations in 2003, development projects such as mines have carried out EIAs and suggested mitigation measures to address the identified impacts. Yet, while such provisions are a welcome reflection of a desire to promote environmental sustainability within the mining industry, an evaluation of the quality of EISs to examine how well the proposed mitigation measures are working is nonexistent. The works of Ravengai et al. (2005a), Makore and Zano (2012) and Meck (2013) demonstrate that mining activities continue to adversely impact on the environment despite such projects being subjected to ElA studies as required by the law. 
To address this gap, this paper evaluated the quality of ElSs for selected mines operating along the Great Dyke of Zimbabwe as a potential indicator of the effectiveness of mitigation measures proposed during EIA. Based on the literature review, a framework of EIS quality as indicator of mitigation effectiveness in EIA was developed. The framework discusses EIS review areas that drive mitigation effectiveness in EIA.

\section{Conceptual framework: quality of EIS as an indicator of mitigation effectiveness}

The EIS is considered the technical heart of the EIA process (Sok 2014). As the main mechanism through which EIA information is reported and accessed, its quality is regarded as critical to the effectiveness of its proposed mitigation measures (Barker and Jones 2013). Environmental impact assessment (EIA) effectiveness is defined as the degree to which EIA is successful in meeting its objectives and purpose (Peterson 2010). Sadler (1996: 37) defines effectiveness as "how well something works or whether it works as intended and meets the purposes for which it is designed." The objectives and purpose of mitigation in EIA are stated as influencing decision making and contributing to sustainable development (Glasson et al. 2005). Sadler (1996) divides effectiveness into three categories: procedural, substantive, and transactive. Procedural effectiveness assesses the degree of compliance with established regulations, standards, and guidelines (Morrison-Saunders and Bailey 2009). Substantive effectiveness focuses on the achievement of the set objectives, while transactive effectiveness is achieved where the outcomes are obtained with least cost in the minimum time frame (Glasson et al. 2005). Theophilou et al. (2010) suggest that substantive effectiveness is demonstrated through changes to the project plan or program being assessed in order to realize the goals of EIA.

The ability of EIA in meeting its objectives and purpose depends on several interlinked factors (Peterson 2010). In this framework, the quality of EIS as an indicator of mitigation effectiveness is addressed. Conceptualizing EIS quality as an indicator of mitigation effectiveness is intended for determining the extent to which ElS influences decision making, based on its quality. Mitigation measures proposed in EIS are considered the foundation (Marshall 2001) or heart (Wood 2003) of EIA. The fact that the EIS is the primary and most important tangible source of information decision makers are provided with to make informed decisions is not debatable (Polonen 2006). The document contains information that informs decision makers and the public about the environmental consequences of the project and facilitates appropriate measures that can be used to mitigate the identified impacts. What is debatable, though, is the quality of information in EIS and its appropriateness in facilitating better decisions (Lee et al. 1999; Tinker et al. 2005; Polonen 2006). According to Lee et al. (1999: 35) "it is the appropriateness and quality, and not the volume of information provided which is the relevant consideration."

The types of mitigations listed in ElSs should be in order of their desirability for addressing adverse effects. According to Mitchell (1997), mitigation refers to measures used to avoid, minimize, repair, and compensate adverse impacts, and enhance positive impacts of project development activities, in that hierarchical order. In a preferential sense, avoidance is considered more desirable and compensation least desirable (Tinker et al. 2005). In Hayes and Morrison-Saunders view (2007), every effort should be made to suggest avoidance measures first, then minimize, and only then compensate the damage as the last resort. Perceived this way, avoidance actions are perceived to result in an environmental quality outcome the same as the baseline environmental condition and compensation the least (Marshall 2001; Tinker et al. 2005). This approach has been adopted by many regulators internationally when approving or rejecting EISs for different projects submitted by project proponents for funding (Hayes and Morrison-Saunders 2007). The existence a hierarchy of mitigation measures, however, also suggests that all impacts cannot be avoided in reality (Marshall 2001).

In order to assess the effectiveness of mitigation measures proposed in EIS, a baseline of ElA practice is essential (Sandham et al. 2005). Understanding baseline data sets the benchmark for judging the effectiveness of implemented mitigation measures during monitoring (Kubo et al. 2009). Mitigation measures are also emphasized in the ElA process once the extent of the potential impacts is well understood.

\section{Methodology}

The study methodology was based on content analysis of EIA regulations and EISs for selected mining projects along the Great Dyke of Zimbabwe. The EISs were reviewed focusing on baseline information, impact identification and evaluation, and alternatives and types of mitigation measures proposed. The modified Lee and Colley (1992) review package and Mitchell's (1997) mitigation hierarchy guidelines were used to review the quality of EISs and types of mitigation measures, respectively. The two packages are used worldwide, and the results obtained using them can be compared to other similar studies in different countries. 


\subsection{Study area}

The ElSs investigated were for mines operating along the Great Dyke of Zimbabwe (Fig. 1), a mineral rich belt spanning about $550 \mathrm{~km}$ long and 4-11 km wide (Makore and Zano 2012). The Great Dyke was selected for four main reasons. Firstly, it contains significant quantities of mineral deposits, including: platinum group of metals (PGMs), chrome, gold, nickel, asbestos, magnetite, and copper that are under exploitation (Chakupa 2011). Secondly, based on its mineral abundance, the majority of mine ElAs have been undertaken along the Great Dyke. Thirdly, many mining activities impact negatively on the environment despite such projects being subjected to EIA studies as required by the law (Meck et al. 2006). The study provided a unique opportunity to assess the quality of such EISs and their influence on the effectiveness of its proposed mitigation measures. A study of this nature could shed some light on the barriers to the quality of produced EISs and the challenges to the likely effectiveness of the proposed mitigation measures. Lastly, the Great Dyke is dominated by both large and small-scale mining activities (Makore and Zano 2012). Hence, the Great Dyke offered the opportunity to review the quality of ElS for both large- and small-scale mines. Figure 1 shows the location of two ElSs focusing on largescale platinum-smelting plant and mine used in this study: Selous Metallurgical Complex platinum-smelting plant and Ngezi platinum mine.

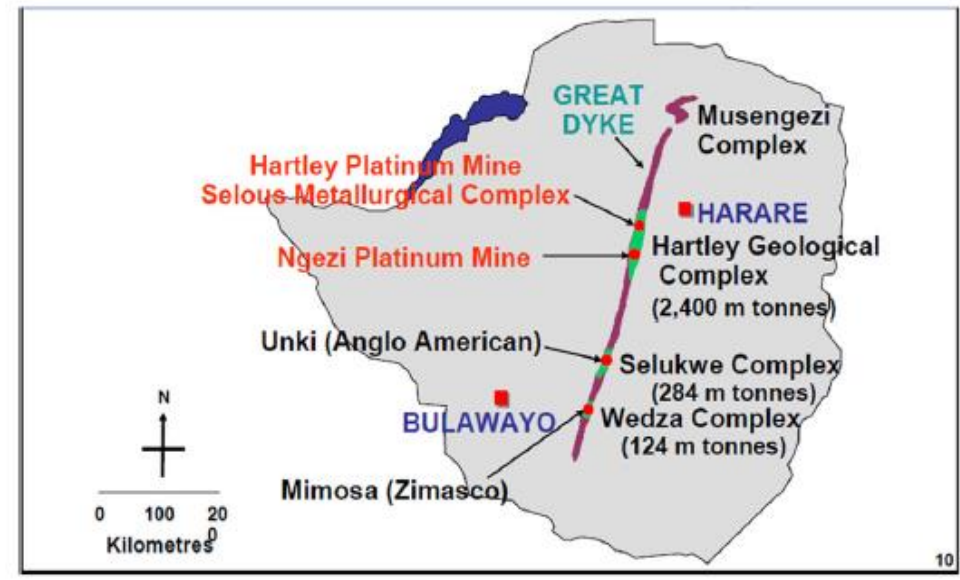

Source Zimplats Environmental Quartely Report (2012)

Fig. 1 Platinum mines operating along the Great Dyke

\section{2. $\quad$ Selecting the EIS sample}

Access to EISs was first sought from the Environmental Management Agency (EMA) library, but these were considered confidential and inaccessible to third parties such as researchers. On that basis, it was not possible to establish the EIS population along the Great Dyke for the review period. The study then relied on ElSs provided by consenting project proponents and EMA-registered EIA consultants.A purposive sample was made for the review. Purposively, ElSs reviewed were for mines and carried out between 2003 and 2010. The year 2003 is when EIA became a legal requirement, while 2010 gave time lag for judging whether implemented mitigation measures were effective, another issue not covered in this paper. Project proponents were purposively sampled from telephone directory for the area under review. It was emphasized to consenting sources that the required EISs were for mines located along the Great Dyke, similar to those submitted and approved by EMA and carried out between 2003 and 2010. EMA-registered consultants were purposively sampled on the basis of whether they carried ElAs for any mine along the Great Dyke.

A total of $36 \mathrm{ElSs}$, similar to those approved by the Zimbabwe's Environmental Management Agency, were obtained for review. Out of the 36 submitted EISs, 13 were carried out after 2010 and therefore considered ineligible for review according to the set criteria. One EIS had some missing pages and was therefore excluded. In total, a sample of 22 EISs was selected for review. The EIS sample size used compared well with previous samples used elsewhere. Androulidakis and Karakassis (2006) for example reviewed a total of 37 EISs when evaluating the quality of EISs in Creece, while Nadeem and Hameed (2006) reviewed four in Pakistan and Sandham et al. (2008) assessed 20 ElSs for mines in South Africa. 


\subsection{Conducting the ElSs review}

Before embarking on a review of the sampled EISs, the country's EIA regulations were reviewed in order to determine whether the regulatory requirements were followed. In Zimbabwe, the EIA legislation dictates the review sections that should be included in EISs. A description of the regulations and key review areas to be discussed in the EISs provided the foundation for examining some of the factors influencing the quality of reviewed EISs. The EISs review focused on three review areas: baseline, impact identification and evaluation, and alternatives and mitigation. The baseline information reviewed included physical, biological, and social environments before project development activities commenced. This provided the basis for judging on whether the proposed mitigation measures were effective or not by comparing baseline data with monitoring data after development activities commenced. Impact identification and evaluation review area was in terms of definition of impacts, impact identification methods, and assessment of impact significance, as prescribed in the Lee and Colley (1992) EIS quality review package. The third stage pertained to reviewing the alternatives, mitigation measures, and monitoring.

Figure 2 shows the schematic diagram of how the review was carried out. The review process commenced at the subcategories level. Each sub-category was appraised and assigned an assessment symbol. The assessment symbols assigned to the sub-categories were then used to appraise each of the review categories until the overall assessment was completed (Table 1). Each review was graded from A to $F$, with $A$ being of the highest standard and $F$ being very unsatisfactory. The better the grade of each reviewed area, the higher the quality of the EIS; and in the context of mitigation measures, the more effective they were presumed to be in practice. The general threshold between a passable ElS and a noncompliant one was grade $\mathrm{C}$.

The Lee and Colley (1992) EIS quality review package suggests that two reviewers assess each EIS in order to avoid bias during evaluation (Lee et al. 1999). The independent reviewers meet to discuss any differences of opinion before integrating their reviews into one based on consensus. Peterson (2010) concurs with this approach, arguing that pair assessment is more critical than individual assessment. For this study, it was, however, not possible to have two independent reviewers. However, to minimize bias, three EISs were repeatedly reviewed at a day interval by the researcher, and the results were compared to the previous ones following the approach previously used by Bond and McGrath (1997). The approach entails re-reviewing the same EIS after some time and then comparing the results with those of previous reviews. Bond and McGrath (1997) used this approach in their previous studies and noted that the results were similar.

Seeking to examine the types of mitigation measures proposed in the EISs, Mitchell's (1997) mitigation guidelines form (Table 2) was used. Mitigation measures proposed in EISs were classified into any of the five types "avoid," "reduce," "repair," "compensate," and "enhance" (Mitchell 1997).

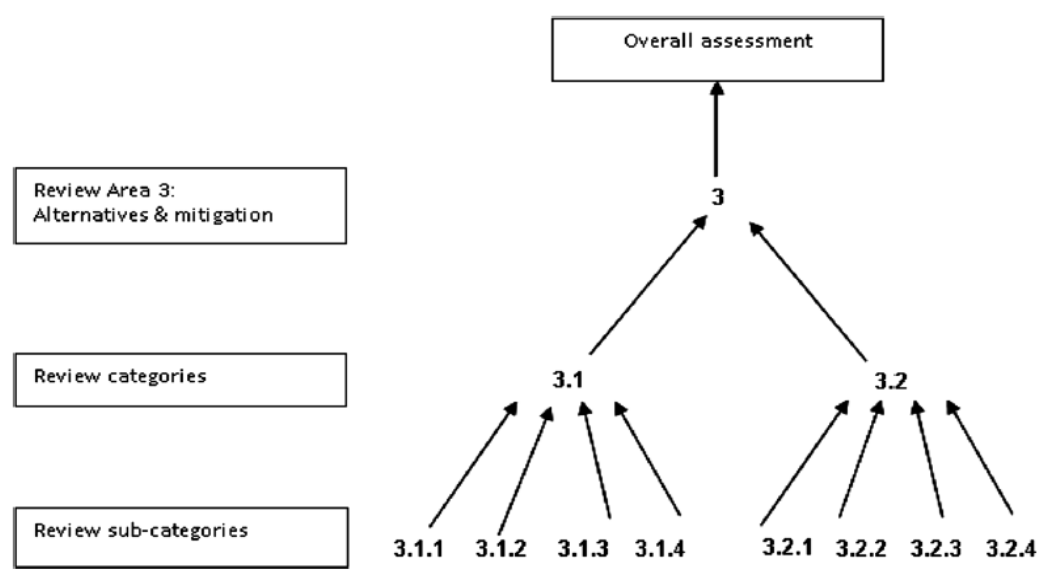

Fig. 2 Adapted hierarchical structure of the Lee and Colley (1992) EIS review package. Source Adapted from Lee and Colley (1992) 
Benchmarking the effectiveness of mitigation measures to the quality...

Table 1 Grade symbols for assessing EIS quality using the Lee and Colley review package

\begin{tabular}{ll}
\hline Symbol & Explanation \\
\hline A & Relevant tasks well performed, no important tasks left incomplete \\
B & Generally satisfactory and complete, only minor omissions and inadequacies \\
C & Can be considered just satisfactory despite omissions and/or inadequacies \\
D & Can be considered just satisfactory despite omissions and/or inadequacies \\
E & Not satisfactory, important task(s) poorly done or not attempted \\
F & Very unsatisfactory, important task(s) poorly done or not attempted \\
Not applicable & Not applicable. The Review Topic is not applicable or is irrelevant \\
& in the context of the statement
\end{tabular}

Source Lee and Colley (1992)

Table 2 Mitchell's (1997) mitigation hierarchy guidelines form

\begin{tabular}{llllll}
\hline Mitigation measure proposed in EIS & \multicolumn{4}{l}{ Type of mitigation } & \\
\cline { 2 - 5 } & Avoid & Reduce & Repair & Compensate & Enhance \\
\hline 1 & & & & & \\
2 & & & & \\
3 & & & & \\
\end{tabular}

The analysis of data was mainly descriptive, using Excel and STATA version 11. throughout this analysis, histograms and pie charts were plotted

Fig. 3 EISs reviewed by year of submission

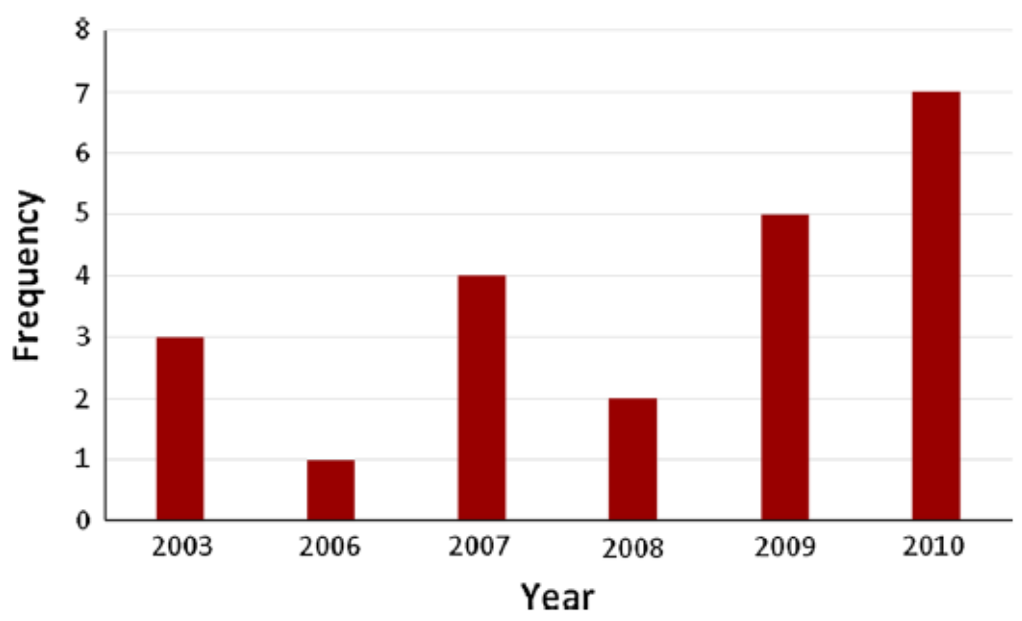




\section{Results}

The overall distribution of the reviewed ElSs by year of production is shown in Fig. 3 . The sizes of ElSs ranged between 56 and 152 pages. The two ElSs focusing on large-scale mining sites had the highest number of pages, 152 on average.

\subsection{EISs legislative provisions}

In Zimbabwe, the Environmental Management Act (chapter 20:27) requires project proponents to produce EISs prior to undertaking development projects affecting the quality of environment. The regulations compel project proponents to submit EISs to the country's EIA authority, the Environmental Management Agency (EMA) for scrutiny before making the final decision. Once the EIS is submitted, the authority's technical review panel comprising of a district, province, and national environmental officers determine the quality of EIS and make recommendations. The duration of this process is 60 days after receiving the EIS. Based on the outcome of the review, the authority can accept, reject, or recommend further modifications to avoid future confrontation. If the EIS is accepted, an EIA license is issued to the proponent. There are seven major review areas of the EIS in the legislation, namely: (1) description of the project and its activities to be undertaken; (2) reasons for selecting the project site; (3) description of the likely impacts of the project on the environment; (4) measures to be undertaken by project proponents to eliminate, reduce, or mitigate any anticipated adverse impacts on the environment as well as identify ways of monitoring and managing the environmental impacts of the project; (5) indicate whether the environment of any other country is likely to be impacted by the project and measures to be taken to minimize such impacts; (6) indicate how the proponent proposes to integrate biological diversity in the project; and (7) describe the methodology used by the proponent to compile the EISs. Based on the contents of EISs raised in the regulations, the preparation of EIS does not specify or recommend any baseline studies. The regulations seem to assume that EIS preparers will automatically describe the baseline environment during the description of the project and its activities.

Part XI (99) (d) of the Environmental Management Act (chapter 20:27) define "mitigation" as "eliminating," "reducing," or "mitigating" any anticipated adverse effects of the project on the environment (Government of Zimbabwe, GOZ 2003). Section 107 (1) further requires that: Every developer shall take all reasonable measures to prevent or, if prevention is not practicable, to mitigate any undesirable effect on the environment that may arise from the implementation of his project (GOZ 2003: 391). While avoidance and reduction are clearly specified as concrete types of mitigation, there is no sequencing of these actions, nor are the actions of repairing, compensation and enhancement provided.

\subsection{Description of the baseline information}

Seven key environmental categories were described under the baseline in the 22 EISs. These included water, flora, fauna; soil, air, socioeconomic, and cultural environments. The description of baseline environment was variable in quality, with 73 \% of the EISs graded $C$ in terms of description of the environment (category 1.4). The description of the environment was largely narratives based on observations and with no measurements of raw data. Although all ElSs presented information on the description of the environment, estimates of the baseline environmental condition (category 1.5) were generally unsatisfactory. Only two EISs focusing on large-scale platinum-related mining and smelting specified the soil, water, as well as estimated species richness and abundance in detail. Because of the small sample size of ElS focusing on large-scale mines, it is not conclusive whether this result is applicable to all EISs focusing on large-scale mines. 
Table 3 Environmental aspects in impact identification and mitigation areas of EISs

\begin{tabular}{|c|c|c|c|c|c|}
\hline Nature of impact & $\begin{array}{l}\text { Environmental } \\
\text { aspect impacted }\end{array}$ & $\begin{array}{l}\text { Frequency of } \\
\text { environmental } \\
\text { aspects impacted in } \\
\text { ElSs }\end{array}$ & $\begin{array}{l}\text { Percentage of all } \\
\text { aspects }\end{array}$ & $\begin{array}{l}\text { Number of ElSs covering } \\
\text { the impacts and aspects }\end{array}$ & $\begin{array}{l}\text { Percentage of EISs covering } \\
\text { impact and aspect }\end{array}$ \\
\hline Siltation & Water & 169 & 20.4 & 22 & 100 \\
\hline \multicolumn{6}{|l|}{ Contamination } \\
\hline \multicolumn{6}{|l|}{ Acid mine drainage } \\
\hline \multicolumn{6}{|l|}{ Water depletion } \\
\hline \multicolumn{6}{|l|}{ Flooding risks } \\
\hline Fugitive dust & Air & 71 & 8.6 & 21 & 96 \\
\hline \multicolumn{6}{|l|}{ Exhaust gases } \\
\hline \multicolumn{6}{|l|}{$\begin{array}{l}\text { Gases from mineral } \\
\text { smelting }\end{array}$} \\
\hline \multicolumn{6}{|l|}{ Poor ventilation } \\
\hline Invasive species & $\begin{array}{l}\text { Biodiversity/ } \\
\text { ecology }\end{array}$ & 73 & 8.8 & 22 & 100 \\
\hline \multicolumn{6}{|l|}{ Deforestation } \\
\hline \multicolumn{6}{|l|}{$\begin{array}{l}\text { Biodiversity } \\
\text { Depletion }\end{array}$} \\
\hline Open pits & Soil/land & 65 & 7.9 & 22 & 100 \\
\hline $\begin{array}{l}\text { Soil/land } \\
\text { contamination }\end{array}$ & & & 6 & & \\
\hline Soil erosion & & & 12 & & \\
\hline $\begin{array}{l}\text { Solid and } \\
\text { Hazardous waste }\end{array}$ & Waste & 25 & 3 & 158 & \\
\hline Fire harzards & Fire & 38 & 4.6 & 5 & 23 \\
\hline Ground vibrations & Noise & 56 & 6.8 & 21 & 96 \\
\hline Machinery & Health & 82 & 9.9 & 22 & 100 \\
\hline \multicolumn{6}{|l|}{ Blasting } \\
\hline \multicolumn{6}{|l|}{ HIV?AIDS } \\
\hline \multicolumn{6}{|l|}{$\begin{array}{l}\text { Health } \\
\text { infrastructure }\end{array}$} \\
\hline \multicolumn{6}{|l|}{ Injury, accidents } \\
\hline Occupational issues & Safety & 70 & 8.4 & 20 & 91 \\
\hline Jobs for locals & Socioeconomic & 111 & 13.4 & 22 & 100 \\
\hline $\begin{array}{l}\text { Conflicts over } \\
\text { compensation of } \\
\text { land }\end{array}$ & & & 19 & & \\
\hline \multicolumn{6}{|l|}{ Increased crime } \\
\hline \multicolumn{6}{|l|}{$\begin{array}{l}\text { Improved quality } \\
\text { of life }\end{array}$} \\
\hline Wildlife loss & wildlife & 4 & 0.5 & 4 & 18 \\
\hline Construction & Infrastucture & 28 & 3.4 & 9 & 41 \\
\hline $\begin{array}{l}\text { Destruction of } \\
\text { archeological sites }\end{array}$ & Cultural & 6 & 0.7 & 3 & 14 \\
\hline
\end{tabular}


The description of the baseline socioeconomic environmental conditions related to issues such as existing economic and HIV and AIDS were rather weak. Only $9 \%$ of the EISs were rated satisfactory in this category.

\subsection{Quality of ElSs in terms of impact identification and evaluation}

A total of 919 impacts were identified in the 22 reviewed ElSs. The operations phase had the highest number of impacts, accounting for $79 \%$ of the identified impacts. The construction phase with 137 (15\%) impacts had the second highest number. The decommissioning phase had the smallest number at $55(6 \%)$ impacts. Table 3 summarizes the major environmental aspects and impacts described in the reviewed EISs. The common impacts associated with gold and platinum group metals (PCMs) mining and processing activities were related to acid mine drainage pollution of surface and underground water and siltation of surface water bodies. The chemicals attributed to pollution were mercury, cyanide, and sulfides from gold panning, rock waste dumps, and tailing dams. Air pollution issues emphasized in two EISs on PGMs mining and included fugitive dust particles, carbon dioxide, and sulfur dioxide. Drilling, blasting and fugitive dust attributed for more than $88 \%$ of the air pollutants in all the 22 EISs. Emissions of these pollutants were viewed as potentially harmful to both human health and the environment. Ecological impacts were highlighted mainly in relation to the actual mining activities and their physical disturbances. Increased demand for wood from workers as a fuel was highlighted as a significant threat to forests in 13 of the 22 EISs. Invasive species invasions were reported in six EISs.

Noise pollution was reported in 21 of the 22 EISs. Most of the noise was attributed to the blasting, ground vibrations, and machinery movement. Of the 56 noise cases reported, $37(66.1 \%)$ were attributed to blasting and related ground vibrations. The remaining $34.9 \%$ were attributed to noise from machinery. Noise pollution was also reported to frighten animals as well as interfere with their breeding. Archeological and wildlife impacts were the least represented impacts at $0.5 \%$ of the total impacts. Socioeconomic impacts were largely related to employment, conflicts resulting from unfair compensation, crime, resentments to relocations, and infrastructural developments. Positive socioeconomic benefits were over emphasized in $86 \%$ of the EISs. Negative impacts such as issues of land disputes, prostitution and crime, compensation disagreements were highlighted in $23 \%$ of the EISS. The overall quality of EISs in terms of impact identification indicated that $68 \%$ of the EISs were of satisfactory (grades A-C) quality. The most common grade was B (generally satisfactory), followed by $\mathrm{C}$ (just satisfactory). More than $41 \%$ of the ElSs were rated unsatisfactory in category 2.4. This category deals with the impact identification methodologies. Most of the EISs relied on arbitrary qualitative methods in their impact prediction. As a followup with these EISS, prediction of impacts was identified as deficient. Comparatively, two EISs focusing on large-scale mines provided detailed methodologies. The subcategory dealing with stakeholders' consultation (sub-category 2.3.5) revealed that 20 of the 22 EISs were graded as satisfactory. All the EISs contained enough information on numerous public consultations between project proponents and residents of affected communities as well as relevant statutory bodies. The number of stakeholders consulted, however, varied with each EIS reviewed. In $19 \mathrm{EIS}$, the number of stakeholders consulted ranged between 10 and 15 . In three EISs including all the two focusing on large- scale mines, the number of stakeholders consulted exceeded 30 and included stakeholders with indirect interests such as policy makers and water users downstream of the projects. 
Fig. 4 Quality of EISs in terms of impact identification and evaluation
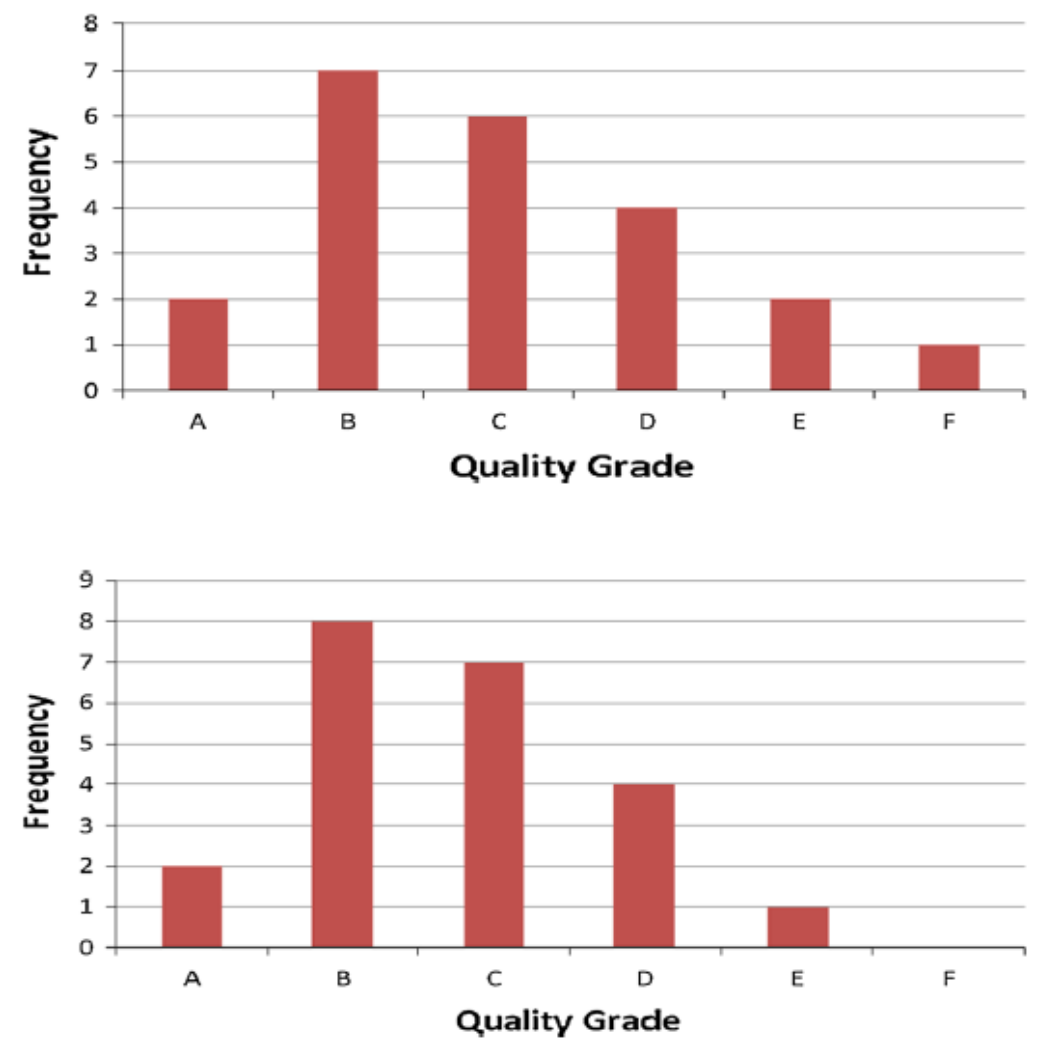

Fig. 5 Quality of EISs in terms proposed mitigation measures

\subsection{Quality of ElSs in terms of alternatives and mitigation measures}

The ratio of proposed mitigation measures to identified impacts was 908:919, respectively. The proposed mitigation measures matched identified impacts. Most mitigation measures presented were for direct impacts of projects. Like in the impact identification, the operational phase received the highest number of mitigation measures at 567 (62.4\%). The construction phase was second in terms of mitigation measures allocation at 208 (23\%). The decommissioning phase had the lowest number of mitigation measures at 195 (21.3\%). The principal mitigation measures mentioned in ElSs were avoiding water pollution, controlling erosion and sedimentation caused by mining activities, comprehensive management of all forms of waste, compensatory measures for destroyed forests, and protecting wildlife from human activities such as poaching (Fig. 4). The distribution of other mitigation measures by environmental aspect included ecology $(12.3 \%)$, socioeconomic benefits $(10.7 \%)$, land degradation (9.9\%), noise pollution ( $8.5 \%)$, air pollution $(4.6 \%)$, fire hazards $(4.4 \%)$, and health hazards (4.3\%). About $77 \%$ of the EISs were graded satisfactory in terms of the alternatives and mitigation review area (Fig. 5). The most unsatisfactory was category 3.1, which deals with alternatives. The "no-action scenario" was the most recommended in $68 \%$ of the EISs. Two EISs (9 \%) focusing on large-scale mines suggested design alternatives to avoid some impacts. In these two cases, technical alternatives were provided on hazardous waste landfill developments, followed by alternative processes for treating acid mine drainage (Table 4). 
Table 4 Mitigation measures proposed in ElSs

\begin{tabular}{|c|c|c|c|c|}
\hline $\begin{array}{l}\text { Environmental } \\
\text { issue impacted }\end{array}$ & Nature of impact & Mitigation measures proposed & $\begin{array}{l}\text { Number of ElSs } \\
\text { with mitigation }\end{array}$ & $\begin{array}{l}\text { Percentage of total } \\
\text { EISs }\end{array}$ \\
\hline \multirow[t]{4}{*}{ water } & Siltation & $\begin{array}{l}\text { Restricting movement of machinery to } \\
\text { designated areas, minimizing vegetation } \\
\text { clearance, earthworks management, } \\
\text { contour ridges, re-vegetation }\end{array}$ & 22 & 100 \\
\hline & Contamination & $\begin{array}{l}\text { Constructing standard tailings ams/ponds, } \\
\text { monitoring, training workers, waste } \\
\text { stabilization, recycling, treating acid mine } \\
\text { drainage, control storm water, fence } \\
\text { ponds and tailings dams }\end{array}$ & 16 & 72 \\
\hline & Water depletion & $\begin{array}{l}\text { Rain water harvesting, restricting water } \\
\text { use }\end{array}$ & 7 & 32 \\
\hline & Flooding risks & $\begin{array}{l}\text { Pumping out excess water, water } \\
\text { diversion }\end{array}$ & 4 & 18 \\
\hline \multirow[t]{4}{*}{ Air } & Fugitive dust & $\begin{array}{l}\text { Sprinkle water on surface, dust } \\
\text { suppression measures, restricting } \\
\text { movement, provision of safety clothes to } \\
\text { workers, regular checkup for workers, } \\
\text { health education, vegetate rock waste } \\
\text { dumps }\end{array}$ & 22 & 100 \\
\hline & Exhaust gases & Maintain machinery, monitoring & 6 & 27 \\
\hline & $\begin{array}{l}\text { Gases from mineral } \\
\text { smelting }\end{array}$ & $\begin{array}{l}\text { Maintain machinery, monitoring, invest } \\
\text { in new technologies, clean gases }\end{array}$ & 3 & 14 \\
\hline & Poor ventilation & $\begin{array}{l}\text { Ensure adequate shaft ventilation, } \\
\text { monitoring }\end{array}$ & 2 & 9 \\
\hline \multirow[t]{3}{*}{ Ecology } & Invasive species & $\begin{array}{l}\text { Destroy all alien invasive species, } \\
\text { environmental education }\end{array}$ & 3 & 14 \\
\hline & Deforestation & $\begin{array}{l}\text { Minimize vegetation removal, restrict } \\
\text { clearance to desired areas only, } \\
\text { compensate destroyed forests, establish } \\
\text { indigenous vegetation seed banks, create } \\
\text { green banks, rehabilitate disturbed } \\
\text { areas with similar vegetation as before, } \\
\text { establish indigenous tree nurseries }\end{array}$ & 17 & 77 \\
\hline & $\begin{array}{l}\text { Biodiversity } \\
\text { Depletion }\end{array}$ & $\begin{array}{l}\text { Restrict ecosystem disturbance, } \\
\text { environmental awareness, preserve } \\
\text { endangered species }\end{array}$ & 5 & 23 \\
\hline \multirow[t]{3}{*}{$\begin{array}{l}\text { Soil/land } \\
\text { degration }\end{array}$} & Open pits & $\begin{array}{l}\text { Rehabilitate all open pits, backfilling, land } \\
\text { reclamation, plant trees and grass on } \\
\text { rehabilitated lands, stock material for } \\
\text { reclamation }\end{array}$ & 10 & 45 \\
\hline & $\begin{array}{l}\text { Soil/land } \\
\text { contamination }\end{array}$ & $\begin{array}{l}\text { Minimize oil leakages, construct standard } \\
\text { ponds and tailings dams, monitor soil } \\
\text { quality regularly }\end{array}$ & 6 & 27 \\
\hline & Soil erosion & $\begin{array}{l}\text { Construct contour ridges where slope is } \\
\text { steep, institute erosion control measures, } \\
\text { use waste rock to maintain roads, } \\
\text { rehabilitate gullies }\end{array}$ & 12 & 22 \\
\hline Landscape & Excavations & Reclamation of degraded lands & 3 & 14 \\
\hline waste & $\begin{array}{l}\text { Hazardous } \\
\text { chemicals }\end{array}$ & $\begin{array}{l}\text { Training, awareness, provide waste bins } \\
\text { to employees }\end{array}$ & 8 & 36 \\
\hline Fire hazards & Fire harzards & $\begin{array}{l}\text { Prevent fires in fire-prone areas, maintain } \\
\text { fire equipment, train workers in fire } \\
\text { fighting, createfire guards }\end{array}$ & 5 & 23 \\
\hline noise & Ground vibrations & $\begin{array}{l}\text { Provide workers with ear plugs, warning } \\
\text { sirens }\end{array}$ & 6 & 27 \\
\hline \multirow[t]{2}{*}{ health } & Machinery & $\begin{array}{l}\text { Provide workers with ear plugs, restrict } \\
\text { vehicle movement }\end{array}$ & 13 & 59 \\
\hline & Blasting & $\begin{array}{l}\text { Provide workers with ear plugs, warning } \\
\text { sirens, confine blasting to day time, } \\
\text { monitor blasting }\end{array}$ & 14 & 64 \\
\hline
\end{tabular}




\begin{tabular}{|c|c|c|c|c|}
\hline & HIV?AIDS & $\begin{array}{l}\text { Provide workers condoms, health } \\
\text { education, employ locals }\end{array}$ & 16 & 72 \\
\hline & Health infrastructure & Build new clinics, awareness programmes & 12 & 55 \\
\hline $\begin{array}{l}\text { Occupational } \\
\text { and Safety } \\
\text { issues }\end{array}$ & Injury, accidents & $\begin{array}{l}\text { Ensure adequate ventilation, establish } \\
\text { safety rules, provide protective } \\
\text { equipment, train workers on safety issues, } \\
\text { service machinery, regular checkup for } \\
\text { workers, rescue team in place, } \\
\text { awareness programmes, establish safety } \\
\text { procedures, establish safety benchmarks }\end{array}$ & 22 & 100 \\
\hline \multirow[t]{4}{*}{ Socioeconomic } & Jobs for locals & Give first preference to locals for all jobs & 22 & 100 \\
\hline & $\begin{array}{l}\text { Conflicts over } \\
\text { compensation of } \\
\text { land }\end{array}$ & $\begin{array}{l}\text { Ensure that compensation for lost land } \\
\text { and other resources is fair, maintain } \\
\text { dialog with local communities, monitor } \\
\text { communities' water quality }\end{array}$ & 19 & 86 \\
\hline & Increased crime & $\begin{array}{l}\text { Introduce police patrols, crime awareness, } \\
\text { screen all employees }\end{array}$ & 17 & 77 \\
\hline & $\begin{array}{l}\text { Improved quality of } \\
\text { life }\end{array}$ & $\begin{array}{l}\text { Build infrastructure for local communities, } \\
\text { employ locals, cumulative investments in } \\
\text { local communities, offer better salaries, } \\
\text { provide accommodation }\end{array}$ & 21 & 95 \\
\hline Wildlife & Poaching & $\begin{array}{l}\text { Awareness, criminalize poaching, } \\
\text { minimize wildlife habitat destruction }\end{array}$ & 4 & 18 \\
\hline Cultural & \begin{tabular}{|l|} 
Destruction of \\
archeological sites
\end{tabular} & Look out for any areas of cultural interest & 3 & 14 \\
\hline
\end{tabular}

The plan details of how proposed mitigation measures were to be implemented and monitored were provided in $86 \%$ of the EISs. The prescribed features that needed to be monitored and frequency of monitoring were clearly articulated in these EISs. However, no performance standards with which the effectiveness of implemented mitigation measures was to be measured against were provided.

\subsection{Mitigation measures proposed in ElSs The mitigation included in EISs by type is shown in Fig. 6.}

The greatest number of types of mitigation measures focused on impact reduction (Fig. 6). Impact reduction actions were more than twice the second highest type of mitigation measure proposed as shown in Fig. 6. Table 5 shows the specific actions aimed at reducing the impacts that were proposed. Dust suppression measures, improved ventilation, and establishment of safety rules, putting in place rescue teams, and awareness measures were covered by all 22 EISs. The least proposed reduction measures focused on constructing interceptors to collect used oils (one EIS) as well as waste collection (five EISs). Avoidance measures constituted $23.61 \%$ ) of the 908 mitigation measures indentified in the ElSs. The most avoided environmental impact related to water and ecology. Environmental control measures comprising actions to avoid included avoiding unnecessary vegetation clearance and use of hazardous chemicals. In relation to health impacts, avoidance measures included use of personal protective equipment, HIV and AIDS warning signs, and sex education awareness programs. Alternatives aimed at avoiding some impacts included the engineering design of the solid waste landfill through the layering of the surface with impermeable clay material in order to prevent leachate leaching and thus prevent underground water pollution. It was proposed that the generated leachate be collected for treatment before being released into the environment. 


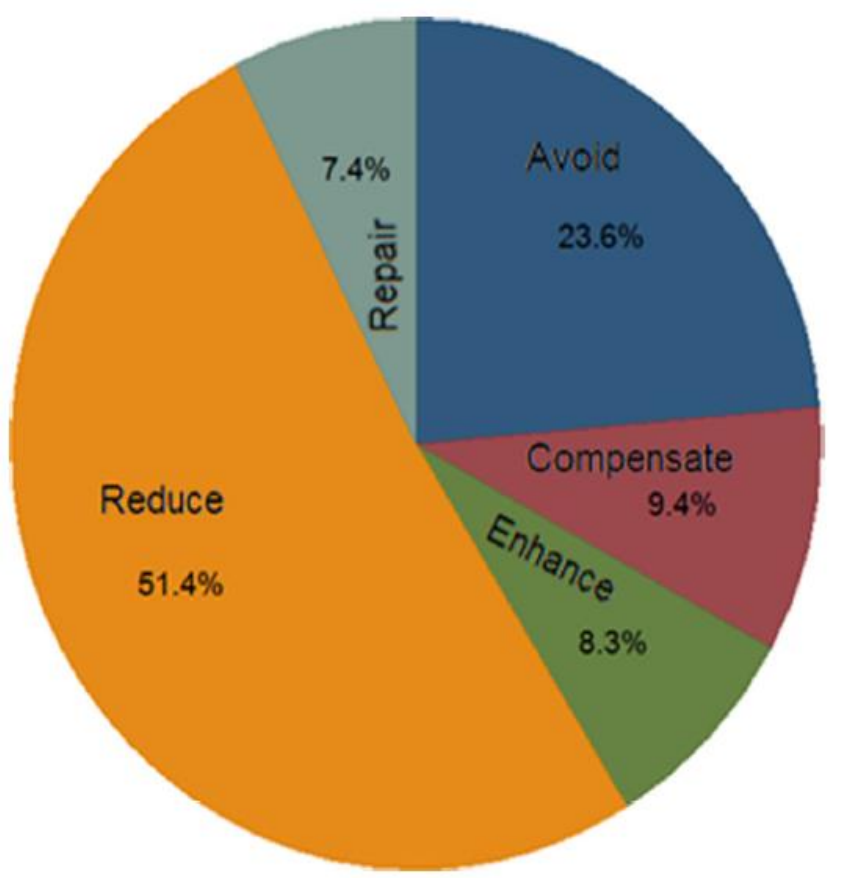

Fig. 6 Types of mitigation measures proposed in EISs 
Table 5 Measures proposed to minimize environmental impacts

\begin{tabular}{lc}
\hline Mitigation measure recommended & $\begin{array}{l}\text { Number of EISs } \\
\text { recommending } \\
\text { the mitigation measure }\end{array}$ \\
\hline Dust suppression & 22 \\
Monitoring & 22 \\
Acid mine drainage management & 11 \\
Water treatment & 16 \\
Rain water harvesting & 7 \\
Flood risk management measures & 4 \\
Minimizing vegetation clearance & 17 \\
Soil erosion management & 12 \\
Management of chemicals and their storages & 16 \\
Putting in place oil interceptors & 1 \\
Waste segregation at source & 5 \\
Providing workers with ear plugs and restricting vehicle movement & 13 \\
Warning sirens before blasting & 9 \\
Confining blasting to certain time periods & 9 \\
Providing workers with condoms to minimize HIV/AIDS spread & 16 \\
Ensuring adequate ventilation for underground shafts & 22 \\
Establishing safety rules and providing workers with protective & 22 \\
equipment & 22 \\
Regular checkup for workers & 22 \\
Putting in place rescue teams in case of accidents & 22 \\
Fair compensation for lost land and other resources to minimize conflicts & 19 \\
Introducing police patrols to minimize crime & 17 \\
Minimizing wildlife habitat destruction & 4 \\
Putting in place warning signs & 22 \\
\hline & 2 \\
\hline
\end{tabular}

Other preventive designs included technology at the tailings to prevent acid mine drainage from polluting underground water, and the construction of underground hazardous waste storage tanks where treated hazardous solid waste would be permanently stored. Impact repairing was recommended in $77 \%$ of the ElSs. The forms of remediation included the treatment of contaminated soils, treatment of sick workers, water recycling, and treatment of contaminated water. Repairing, however, accounted for the least number of mitigation measures, at only $7.4 \%$ of the recommended mitigation measures. Compensatory measures constituted $9.4 \%$ of the proposed 908 mitigation measures and focused on the rehabilitation of the degraded lands and restoring destroyed vegetation. Restoration of the indigenous trees and grasses was recommended in 77 $\%$ of the EISs. Measures such as creating indigenous green banks, replacing lost vegetation, seed harvesting, and planting were commonly proposed. Replacing the lost habitat which could not be restored was proposed in $23 \%$ of the ElSs. Impact enhancement actions were associated with the positive socioeconomic expectations. The enhancing measures focused on employment of the locals, improved service delivery, new infrastructure, and improvement of general standard of living. 


\section{Discussion}

The main objective in undertaking this study was to gain a better understanding of the quality of EIS and its likely influence on the effectiveness of its proposed mitigation measures. A framework was introduced based on the literature to assess the quality of EIS as an indicator of the likely effectiveness of proposed mitigation measures. The results showed that the quality of $77 \%$ of reviewed EISs was satisfactory in terms of proposed mitigation measures. The influence of such ElSs on decision making cannot be doubted. The result contributes to the scientific knowledge on how mitigation performance is influenced by quality of EISs. The results also provide some limited support for the proposition that the EISs can be used for decision making or for the proposition that they can be used for decision justification. Because of the legal requirement, project proponents are bound to consult such EISs especially if the regulations are enforced by the EIA authority.

Provision for monitoring the effectiveness of mitigation measures proposed in EISs was included in $86 \%$ of the 22 reviewed EISs. This provision reflects the general measures put in place to assess the effectiveness of proposed mitigation measures. Since monitoring is mandatory according to the regulations, there is some form of guarantee that the identified impacts will be mitigated in accordance with the undertakings made in EISs. On that basis, some of the proposed mitigation measures have potential to be effective in protecting the environment from mining activities. It is, however, difficult to determine whether mitigation measures proposed in ElSs would be effective in compensating lost habitats given its absence in the regulations and low coverage in EISs. There is a considerable risk that significant adverse ecological impacts will not be compensated and much of the natural habitat will be lost as proponents are not legally obliged. Some indications also need to be given of the effectiveness of the proposed measures, based on some standards criteria (Treweek and Thompson 1997).

The EIS review system is the responsibility of EMA, which bases its review on expertise of its environmental officers at district, province, and national center. On that basis, the quality of reviewed EISs cannot be viewed in isolation of the EIA regulations. Analysis of EIS quality showed high variation, especially between those focusing on large- and small-scale mines, yet they were all approved as being enough to inform decision making. Often, small-scale mine-focused ElSs presented qualitative and poorly analyzed baseline and impacts in a form that did not provide explanation of their significance to the mitigation measures proposed. The copy-paste from previous ElSs without any elaboration of data reduced the quality of most EISs significantly. Based on such results, the review process by the EIA authority technical team fell short of the quality review package indicators for good-quality EISs. Most EISs focusing on small-scale mines had low-quality grades to make informed decision. Against this background, previous studies argue that the EIS review in most developing countries suffer from lack of qualified expertise working in government for such activities (Mwakaje 2013). Yet the importance of such skills is well documented in the literature (Morrison-Saunders and Bailey 2009). The need for autonomous scientific professionals to be involved in reviewing EISs has been argued for in the related literature as an alternative solution to such challenges (Morrison-Saunders and Bailey 2009). The tightening of approval conditions under the current EIA regulations in the country also suggest that adherence to EIA regulations is critical and elevates procedures over substantive measures. As a result, the way mitigation is conceptualized in the regulation could explain some of the gaps identified in ElSs regarding the proposed mitigation measures. Section 99(d) of the Environmental Management Act (Chapter 20:27) conceptualizes mitigation as "eliminating," "reducing," or "mitigating" adverse impacts. While this is already confusing, the failure to provide compensatory measures could be one of the reasons why proponents do not restore natural ecosystems destroyed by mining activities along the Great Dyke. Given that, mining by its nature cannot avoid most ecological issues, compensating degraded forests is essential as part of the conditions under which mining activities should be allowed to go ahead. The view of this study is that compensation of the ecological function of the ecosystem is weak in reviewed EISs and because regulations do not enforce it, proponents are not bound to consider such recommendations in EISs. Having well-defined mitigation criteria could provide an unambiguous measure of the effectiveness of proposed measures.

\section{Conclusion}

This paper introduced a conceptual framework which aims to clarify the relationships between quality of EIS and effectiveness of proposed mitigating measures. The study has shown one way in which this framework can be operationalised. The quality of EIS is useful in indicating the likely effectiveness of its proposed mitigation measures. However, it is only a guide, as the proposed mitigation measures have to be implemented and monitored. The results, however, provide indicative evidence of the likely effectiveness of proposed mitigation measures based on the quality of EISs. While there is considerable room for improvement, the quality of reviewed EISs has potential to contribute some educated judgments during decision making. For this reason, reviewing the quality of EISS is crucial in order to provide feedback mechanisms that effectively protect the environment from project development activities such as mining. The findings show a high degree of variation in the quality 
of EISs focusing on largescale mines and those on small-scale mines. The quality of EISs focusing on large-scale mines was notably better compared with those on small scale. This may be a reflection of funding allocated to ElAs by both large and small scale mines. Small-scale miners appear to be inadequately funding EIA studies in order to avoid costs, and this is done partly because of the perceived weaknesses in the regulatory and enforcement systems. EIS review by the EIA authority itself was also not found to be consistent, given the approval of EISs of such diverse quality. Building the capacity of reviewers, EIA consultants and law enforcers to make the EIA process consistent is recommended. This could reduce the disparities noted in the results. Monitoring and enforcement of approved EIS recommended mitigation measures could also resolve this. The analysis of EIA regulations in Zimbabwe revealed that the concept "mitigation" is vaguely defined as the actions that constitute it do not show any prioritized sequence and therefore do not compel consultants to abide by when proposing mitigation measures in ElSs. Additionally, the absence in the regulations of actions such as compensation for lost environmental values was identified as one of the shortcomings. There is no explicit provision in the EIA regulations for compensation if ecological functions are destroyed by mining activities. If Mitchell's (1997) mitigation hierarchy were to be followed in practice for mining activities, compensation would most likely be the option, given that it is most unlikely to avoid most ecological issues in mining. It is also clear from the analysis of ElSs that while it is an indicator of mitigation effectiveness, the role is limited. A good-quality EIS on its own does little to guarantee the effectiveness of its proposed mitigation measures. There is a strong argument in the literature that such mitigation commitments should be implemented and monitored, re- ported, and audited.

Acknowledgments This work was supported by research grants from the University of South Africa (UNISA) Financial Aid Bureau and the Exxaro Chair in Business and Climate Change of UNISA. We also wish to extend our thanks to consenting proponents and EIA consultants who accessed their ElSs for review. Opinions, findings, and conclusions or recommendations expressed in this paper are those of the author and do not necessarily reflect the views do not necessarily reflect the views 


\section{References}

Androulidakis, I., \& Karakassis, I. (2006). Evaluation of the EIA system performance in Greece, using quality indicators. Environmental Impact Assessment Review, 26, 242-256.

Barker, A., \& Jones, C. (2013). A critique of the performance of ElA within the offshore oil and gas sector. Environmental Impact Assessment Review, $43,31-39$.

Bond, A., \& McGrath, C. (1997). The quality of environmental impact statements: A review of those submitted in Cork, Eire from 1988-1993. Project Appraisal, 12(1), 43-52.

Canelas, L., Almansa, P., Merchan, M., \& Cifuentes, P. (2005). Quality of environmental impact statements in Portugal and Spain. Environmental Impact Assessment Review, 25, 217-225.

Chakupa, T. (2011). Environmental management in chrome mining along the Great Dyke: A case study of ZIMASCO operations. Unpublished MSc, Thesis. University of Stellenbosch: Stellenbosch, South Africa.

Evans, R. (2013). The environmental impact statement: A rhetorical analysis. PhD thesis. Texas Tech University: Texas, USA.

Glasson, J., Therivel, R., \& Chadwick, A. (2005). Introduction to environmental impact assessment (3rd ed.). London, UK: Routledge.

Government of Zimbabwe (GOZ). (2003). Environmental management act (Chapter 20: 27). No. 13/2002. Government Printers, Harare.

Hayes, N., \& Morrison-Saunders, A. (2007). Effectiveness of environmental offsets in environmental impact assessment: Practitioner perspectives from Western Australia. Impact Assessment and Project Appraisal, 25(3), 209-218.

Kabir, S. M. Z., Momtaz, S., Gladstone W. (2010). The quality of environmental impact statement (EIS) in Bangladesh. IAIA10 Conference Proceedings 6-11 April 2010, International Conference Centre Geneva-Switzerland (www.iaia.org).

Kubo, B. M., Were, J. O. \& Wetang'ula, G. N. (2009). Environmental baseline studies for geothermal developments. Paper presented at short Course IV on Exploration for Geothermal Resources, organized by UNU-GTP, KenGen and GDC, at Lake Naivasha, Kenya, November 1-22, 2009.

Lee, N., \& Colley, R. (1992). Review of the quality of environmental statements. Occasional Paper, Vol. 24. Manchester ElA Centre, University of Manchester: Manchester, UK.

Lee, N., Colley, R., Bonde, J., \& Simpson, J. (1999). Reviewing the quality of the environmental statements and environmental appraisals. Occasional paper 55. EIA Centre, University of Manchester: Manchester, UK.

Makore, G., \& Zano, V. (2012). Mining within Zimbabwe's Great Dyke: Extent, impacts and opportunities. Harare: Zimbabwe Environmental Law Association (ZELA).

Marshall, R. (2001). Mitigation in ElA: Application of mitigation and its resolution within environmental impact assessment, an industrial perspective. Impact assessment and Project Appraisal, 19(3), 195-204.

Meck, M. (2013). Geochemistry for sustainable development in Africa: Zimbabwe case study. In A. Gurib- Fakim \& J. Eloff (Eds.), Chemistry for sustainable development in Africa. London: Springer.

Meck, M., Love, D., \& Mapani, B. (2006). Zimbabwean mine dumps and their impacts on river water quality: A reconnaissance study. Physics and Chemistry of the Earth, 31, 797-803.

Mitchell, J. (1997). Mitigation in environmental assessment—furthering best practice. Environmental Assessment, 5, $28-29$.

Morrison-Saunders, A., Arts, J., Baker, J., \& Caldwell, P. (2001). Roles and stakes in environmental impact assessment follow-up. Impact Assessment and Project Appraisal, 19(4), 289-296.

Morrison-Saunders, A., \& Bailey, M. (2009). Appraising the role of relationships between regulators and consultants for effective ElA. Impact Assessment and Project Appraisal, 29(5), 284-294.

Mwakaje, A. G. (2013). Assessing the contribution of environmental impact assessments in informing decision makers concerning the booming of FDI in Tanzania. Environment and Natural Resources Research, 3(4), 118-132.

Nadeem, O., \& Hameed, R. (2006). A critical review of the adequacy of ElA reports-Evidence from Pakistan. International Journal of Human and Social Sciences, 1, 54-61. 
Okafor, N. A. (2008). Evaluation of the effectiveness of the screening criteria developed by the Institute of Environmental Management and Assessment (IEMA) for review of Environmental Impact Statements (EIS) Submitted for Accreditation into IEMA Register of Impact Assessors. MSC Thesis. University of

East Anglia: Norwich, UK.

Ortolano, L., \& Shepherd, A. (1995). Environmental impact assessment: Challenges and opportunities. Impact Assessment, 13, 3-30.

Peterson, K. (2010). Quality of environmental impact statements and variability of scrutiny by reviewers. Environmental Impact Assessment Review, 30, 169-176.

Pinho, P., Maia, R., \& Monterroso, A. (2007). The quality of Portuguese environmental impact studies: The case of small hydro power Projects. Environmental Impact Assessment Review, 27, 189-205.

Polonen, I. (2006). Quality control and the substantive influence of environmental impact assessment in Finland. Environmental Impact Assessment Review, 26, 481-491.

Ravengai, S., Love, D., Love, I., Gratwicke, B., Mandingaisa, O., \& Owen, R. (2005). Impact of Iron Duke Pyrite Mine on water chemistry and aquatic life Mazowe valley, Zimbabwe. Water SA, 31, 219-228.

Sadler, B. (1996). Environmental assessment in a changing world: Evaluating practice to improve per-formance. Final Report of the International Study of the Effectiveness of Environmental Assessment. Canadian Environmental Assessment Agency: Ottawa, Canada.

Sandham, L. A., Hoffmann, A. R., \& Retief, F. P. (2008). Reflections on the quality of mining ElA reports in South Africa. The Journal of the Southern African Institute of Mining and Metallurgy, 108, 701-706.

Sandham, L. A., Siphugu, M. V., \& Tshivhandekano, T. R. (2005). Aspects of environmental impact assessment (EIA) practice in the Limpopo Province-South Africa. AJEAM-RAGEE, 10, 50-65.

Sok, V. (2014). An examination of environmental impact assessment (ElA) practices for effectively ad- dressing climate change issues. PhD thesis. University of Western Australia: Perth, Australia.

Theophilou, V., Bond, A., \& Cashmore, M. (2010). Application of the SEA Directive to EU structural funds: Perspectives on effectiveness. Environmental Impact Assessment Review, 30, 136-144.

Tinker, L., Cobb, D., Bond, A., \& Cashmore, M. (2005). Impact mitigation in environmental impact assessment: Paper promises or the basis of consent conditions. Impact Assessment and Project Ap praisal, 23, 265-280.

Treweek, J., \& Thompson, S. (1997). A review of ecological mitigation measures in UK environmental statements with respect to sustainable development. International Journal of Sustainable Development and World Ecology, 4, 40-50.

Wende, W. (2002). Evaluation of the effectiveness and quality of environmental impact assessment in the Federal Republic of Germany. Impact Assessment and Project Appraisal, 20, 93-99.

Wood, C. (2003). Environmental impact assessment in developing countries: An overview. Conference paper on New Directions in Impact Assessment for Development: Methods and Practice 24-25November 2003, ElA Centre School of Planning and Landscape, University of Manchester: Manch- ester, UK.

Zimplats Environmental Quartely Report (2012). 